\title{
Edificar territórios, governar o sagrado: história da espacialização eclesiástica medieval a partir de um caso (supostamente) controverso
}

\author{
Gabriel de Carvalho Godoy Castanho*
}

Lunven, Anne. Du diocèse à la paroisse. Évêchés de Rennes, Dol et Alet/SaintMalo (Ve-XIII ${ }^{e}$ siècle). Rennes: Presses Universitaires de Rennes, 2014. 432 p.

Anne Lunven nos oferece um ótimo exemplo metodológico e analítico dos estudos históricos da Igreja medieval desenvolvidos nesse início de século XXI. Historiadora e arqueóloga, a pesquisadora pratica em seu livro a interdisciplinaridade e a renovação documental largamente defendida e desejada pela Nova História francesa há cerca de 40 anos. Se, por um lado, o uso de material arqueológico se impóe aos pesquisadores da alta Idade Média (período para o qual dispomos de um número insuficiente de testemunhos escritos), por outro, foi preciso a implementação sistemática de escavaçóes de salvamento a partir dos anos 1970 (sobretudo após meados da década seguinte) e a acumulação de dados, provenientes do que se habituou chamar "arquivos do solo", nas últimas décadas para que passássemos a dispor de informaçóes quantitativamente relevantes e qualitativamente variadas capazes de fornecer bases sólidas para análises históricas do passado nas terras da atual França.

O livro de Lunven nos apresenta toda a riqueza e os limites do estado atual das escavaçōes em três regiôes importantes e que constituíam então a fronteira entre o mundo franco e o mundo bretão. Região de transição cultural e política, a área das dioceses de Rennes, Dol e Alet (cuja sede foi transferida para Saint-Malo em meados do século XII) não escapa a uma dificuldade maior dos estudos arqueológicos atuais, a saber, uma identificaçáo certa da natureza dos traços de ocupaçáo humana encontrados no solo. Grosso modo, a dificuldade repousa sobre o fato de que durante muito tempo (até pelo menos o começo do século XI, muitos lugares de culto - capelas, igrejas etc. — não eram construídos em pedras, mas em madeira, como o eram também os locais de habitação - casas). Tal indefinição na identificação da modalidade de ocupação do solo tem como correlata a questáo da constituição da diocese e da paróquia.

Por muito tempo tidas pelos historiadores como um dos principais legados romanos para a Idade Média, a paróquia e a diocese compóem, atualmente, uma das frentes de 
trabalho mais importantes do que podemos chamar de "nova história da Igreja medieval". De grande importância entre os medievalistas franceses na última década, essa maneira renovada de se estudar a instituição eclesiástica medieval parte de um princípio fundamental bastante simples: conhecer os meios e as etapas de construção dogmática da instituição eclesiástica. Utilizando o termo "dogma” pretendo nomear não apenas as concepçôes intelectuais da fé cristã ligadas à revelação divina e, portanto, tidas pelos fiéis como um conjunto de verdades incontestes, universais e a-históricas. Pretendo com o uso da palavra "dogma” evidenciar a forma como a própria história da instituição eclesiástica (sua ancoragem espacial, a formação de seu corpo profissional e o exercício de seu poder) está associada aos dogmas da Igreja, fazendo com que aquilo que foi o resultado de uma construção histórica (a presença da Igreja neste mundo) seja tomada como uma realidade atemporal tributária de uma suposta vontade divina. Nesse sentido, e por oposição a uma história confessional que por muito tempo dominou os estudos da Igreja medieval, os historiadores têm recentemente posto em causa a ideia de que o quadro territorial dessa instituição tenha sido marcado por uma inércia temporal responsável pela transferência dos quadros imperiais romanos para a instituição eclesiástica medieval.

Como bem lembra Florian Mazel em um dos prefácios à obra, é apenas no século XVII que o primeiro mapa cartográfico apresentando a disposição espacial das igrejas foi produzido. Para os períodos anteriores dispomos do rol de bispados produzido pela administração imperial entre o final do século IV e início do século V (Notícia das Gálias) e do Provincial Romano produzido pela chancelaria pontifical no século XII sob a forma da listagem universal de províncias e dioceses que compunham a cristandade latina. A somatória dessas listas com a ausência de documentação mais detalhada e contínua entre a Antiguidade tardia e a Idade Média central levou historiadores a defenderem a continuidade entre as cidades e as dioceses antigas e medievais por meio de uma suposta territorialidade das paróquias merovíngias. Trabalhando com um quadro regional preciso e com o jogo de escalas paróquia-diocese, Lunven nos apresenta um panorama bastante diferente em que a relação cidade-diocese não é dada, mas sim construída ao longo do tempo seguindo diferentes vias e ritmos. A autora revela ainda substancial enfraquecimento do referencial territorial na composição dos espaços estudados até pelo menos o século XI.

De fato, seguindo de perto a nova história da Igreja medieval evocada anteriormente, a autora traça uma história da polarização espacial em torno do lugar de culto como elemento estruturante da organização social. Assim, de uma alta Idade Média marcada por uma baixa territorialidade do domínio eclesiástico e por uma alta personalização (sob a tutela de verdadeiras famílias sacerdotais, único elemento de ligação entre os locais de culto) passa-se ao estabelecimento de uma polarização hierarquizada a partir da sede da diocese de onde emana o poder episcopal. Tal poder passará, entre os séculos XII e XIII, a ser exercido localmente por 
arquidiáconos e deóes (cada um responsável por uma rede intermediária de locais de culto e seus dependentes). Entre um momento e outro temos um longo processo histórico de afirmação da diocese que se manifesta semanticamente pela difusão do uso do termo diocesis em detrimento de parrochia ou episcopatus. Período de gestação no qual a autora destaca o esforço dos bispos (desde o século IX e, sobretudo, após o século XI) em conquistar, para sua igreja, as regióes em disputa com outros centros de poder. $\mathrm{O}$ aspecto principal desse processo de construção de um território eclesiástico identificado com o que hoje entendemos por diocese teria ocorrido no espaço estudado entre 1050 e 1150 quando os textos escritos passam a diferenciar claramente as terras ligadas ao episcopatus e as áreas dependentes de outros poderes como o pagus.

Ao inserir a Bretanha, tida como uma região sui generis pela historiografia tradicional, na lógica de polarização espacial em torno dos locais de culto por meio do fortalecimento da relação de dominium, a autora demonstra que o caso de Dol, organização episcopal constituída a partir de um antigo mosteiro, é, na verdade, único e não uma regra para a região, como se pensava anteriormente. O livro de Lunven nos indica ainda, e com riqueza de detalhes, o ritmo sob o qual se deu a expansão do poder territorial da Igreja na região: 1) a presença de uma grande quantidade de igrejas em meados do século IX sem que se possa falar propriamente em uma rede (ou seja, conexóes entre os locais de culto) hierarquizada ou mesmo de um tecido paroquial constituído sobre a lógica territorial (até o século XI a tendência geral é o aparecimento de igrejas onde já existem habitantes e não o inverso — ver p. 79); 2) a afirmação de um polo eclesiástico que ao mesmo tempo atrai a população (criação do cemitério) e projeta seu poder de dominium (recebimento de tributos) sob uma rede cada vez mais articulada de igrejas dependentes a partir dos séculos XI e XII (é importante notar que essa alteração na organização social da Igreja é contemporânea ao amplo movimento de reconstrução de locais de culto que passaram então a ser construídos em pedra e não mais em madeira, testemunho da importância adquirida pela manifestação terrestre da instituição eclesial); 3) a encarnação do poder da Igreja por meio do estabelecimento de uma hierarquia administrativa responsável por centralizar o recebimento dos tributos e administrar os sacramentos após o século XII.

Rico em gráficos, mapas e contando com mais de duas dúzias de fotografias coloridas dos sítios estudados, bem como uma série de anexos documentais, o livro segue o formato francês tradicional com uma divisão em três partes, cada uma subdividida em dois capítulos. Seguindo uma lógica cronológica, cada parte apresenta uma etapa na formaçáo da paróquia e da diocese medieval na regiáo estudada. Na primeira parte, após analisar as estruturas eclesiásticas da alta Idade Média, a autora defende a impossibilidade de falarmos em diocese ou em paróquia antes do século XI. A segunda parte aborda as mudanças trazidas pelo pensamento dito gregoriano que teria sido o responsável pela associação entre novas práticas de consagração dos espaços e a 
valorização dos edifícios eclesiásticos, levando a uma concepçáo hierarquizada dos lugares de culto, locais onde "se encarnava o céu" (p. 28). Por fim o texto termina com um estudo dos mecanismos administrativos necessários para a gestão dos territórios eclesiásticos que se encontram entre os séculos XII e XIII quase totalmente formados.

Os dois primeiros capítulos, amplamente fundados em documentação arqueológica, nos oferecem uma argumentação ímpar contra a ideia corrente entre os historiadores de que as dioceses seriam herdeiras das civitates romanas, enquanto as paróquias seriam tributárias das villae galo-romanas e do vici (terras de uma aglomeração secundária). Contrariamente também à historiografia local que via na plou (vocábulo oriundo do romano plebs usado para nomear a forma bretã dada à paróquia) uma comunidade autônoma, Lunven demonstra que a autoridade eclesiástica tinha um caráter pessoal e local antes de se projetar sobre um território (p. 104-122). O caso de Rennes é bastante revelador da dificuldade em se estabelecer uma relação entre os locais de culto e um território habitado sob seu controle uma vez que esta cidade, capital religiosa segundo a documentação escrita, não possui atualmente, em seus arquivos do solo, nenhum indício arqueológico que testemunhe a vida pública ou a existência de habitaçóes entre os séculos IV e X-XI (entre um período e outro dispomos apenas de material funerário, o que confirma a ocupação perene da cidade ao longo dos séculos - ver p. 43-44).

A argumentação da autora se baseia em uma distinção entre poder e espaço, uma vez que sua leitura da documentação diplomática sugere que a referência episcopal empregada nesses escritos indica "mais o reconhecimento de uma autoridade do que o pertencimento ao território da diocese" (p. 59). Tal distinção pode parecer estranha para o leitor contemporâneo acostumado a associação entre as duas esferas (espaço e poder) subjacente a nossas concepçóes atuais de espaço público e de Estado. No entanto, do mesmo modo que as noçôes de "público" e de "Estado" devem ser usadas criticamente quando aplicadas à Idade Média, o uso de "território" deve levar em conta o fato de o período medieval não conceber o espaço (até pelo menos a segunda metade do século XII) como uma entidade homogênea e contínua. A consequência é que o poder medieval se exerce localmente e de um ponto a outro segundo uma economia da salvação cada vez mais centrada na instituição eclesial. Exemplo disso é que uma parcela importante das igrejas que se tornarão centros paroquiais entre os séculos XI e XIII já existia desde a alta Idade Média, ainda que sem projetar seu controle sobre o território. Por outro lado, as igrejas fundadas a partir do século XI por laicos ou decorrentes de desflorestamento (em ambos os casos trata-se de novos locais de culto) não criavam automaticamente novas paróquias (p. 91, 99 e 100).

Os capítulos três e quatro, embora ricos em informaçóes e reflexôes a respeito da organização eclesiástica na área estudada, fornecem poucos elementos novos para a discussão mais geral a respeito da polarização do espaço em contexto de fortalecimento do discurso espiritual por parte dos membros 
da Igreja. Grosso modo, pode-se dizer que a autora compreende os movimentos ditos reformistas dos séculos XI-XII como uma estratégia política mais do que um esforço pela correção das funções eclesiásticas (p. 191). Mesmo assim, a partir da cultura material o livro apresenta elementos interessantes que fortalecem a necessidade da revisão do paradigma historiográfico que defende a existência de uma verdadeira onda de construção de novas igrejas no começo do século XII (na esteira da chamada mutação do ano mil proposta por G. Duby). Material arquitetônico em mãos, Lunven confirma a abertura de diversos canteiros de obras entre os séculos X e XII, mas demonstra não se tratarem de novas construçôes e sim de reformas. $\mathrm{Ou}$ seja, em vez de se falar em multiplicaçáo de locais de culto, devemos falar em mudança na natureza dos prédios já existentes (p. 164 e 176-184). É o que a autora chama de "petrificação da igreja e construção aqui em baixo da Cidade celeste" (p. 176). Tal alteração no continente (igreja) está ligada a uma alteração no conteúdo (comunidade) por meio da revalorização da noçáo de ecclesia em seu aspecto polissêmico (metafórico e metonímico) estudado, entre outros, por D. Iogna-Prat (p. 179).

Por fim, os dois últimos capítulos abordam a formação administrativa das igrejas, condição fundamental para o estabelecimento e a manutençáo das dioceses e das paróquias. No primeiro caso, o século XII aparece novamente como momento capital. Monges e cônegos dispondo de sólida formação intelectual passam a destronar as dinastias episcopais que reinavam na região até então (p. 270-271). A partir daí observamos as chancelarias episcopais de Rennes, Alet e Dol se desenvolverem gradativamente e de forma perene (p. 278-279). Para controlar as igrejas dependentes que se encontram espalhadas, algumas vezes a quilômetros de distância, os bispos passam a empregar uma hierarquia administrativa fundada nos arquidiáconos e nos deôes. Estes são responsáveis, entre outras tarefas, pela coleta dos tributos previamente recolhidos pela escala mais baixa deste novo corpo administrativo, os padres em suas paróquias. De fato, a diocese e a paróquia passam, cada vez mais, a se tornar um referencial fiscal: o centro para o qual convergem os tributos. Contudo, ainda que desde o final do século XI o fiel de uma igreja tenha passado a ser identificado como residente de uma paróquia (p. 325), a preocupação com uma delimitação espacial precisa dessa unidade eclesiástica de base era um fenômeno marginal durante a Idade Média. A definição dos limites paroquiais, quando acontecia, se dava nos seguintes contextos de disputas de fronteiras: em torno da clausura monástica; dentro de um sítio castelão; ao longo da formaçáo de novos centros; durante os trabalhos de arroteamento, quando da divisão do dízimo (p. 336). Todo esse sistema parece ter atingido seu ápice na região durante o século XIII, uma vez que algumas paróquias chegaram a ser suprimidas após esse momento (p. 324).

Ao final do livro algumas conclusóes regionais se impóem: 1) os séculos XI e XII foram um momento capital da organização territorial eclesiástica; 2) os mundos bretão e franco não se diferem em suas estruturas 
eclesiais nem em suas baixas territorialidades eclesiásticas; 3) de uma situação de independência existente entre os homens e um local de culto específico durante o período carolíngio passa-se à hierarquização (sacralização) espacial e social entre os séculos XI e XII.

A variada e abundante documentaçáo utilizada não impediu que a autora realizasse uma análise detalhada e articulada de seu material. $\mathrm{O}$ livro tem o grande mérito de buscar na realidade histórica estudada a definiçấo dos conceitos analíticos utilizados (diocese e paróquia, por exemplo). No entanto, um olhar conceitual atento às abordagens teóricas contemporâneas (como a ampla discussão de geógrafos e filósofos da segunda metade do século XX a respeito da noção de território) e à organização dos grupos religiosos medievais (cônegos regulares e monges são tidos pela autora como simples equivalentes - p. 115 e 235 - e a incerteza na diferenciação ou na semelhança entre cônegos regulares e o capítulo das catedrais p. 285-296) poderia esclarecer o propósito de Lunven e evitar confusóes desnecessárias. No primeiro caso, a apresentaçáo teórica do conceito contemporâneo de território facilitaria a compreensão da alteridade medieval e sua separação entre espaço e autoridade (elementos hoje profundamente imbricados). No segundo, a confusão entre diferentes grupos sociais de religiosos oblitera a importância da emergência da normalização das práticas espirituais no processo de implantação territorial e administrativa da Igreja.

De todo modo, o livro é uma contribuição importante não apenas para os estudiosos da Bretanha, mas também para os medievalistas em geral e mesmo para os modernistas interessados na história da Igreja. De fato, fica claro ao longo dos capítulos que a instituição eclesiástica é o resultado de uma constante construçáo administrativa do espaço. Um processo histórico que abarca também o crescente interesse eclesiástico em controlar os principais momentos das vidas dos fiéis mediante o pagamento de tributos. Será sobre essa base administrativa e moral bem assentada localmente que surgirá o Estado moderno calcado no controle de um território, mas isso já é outra história. 